U.S. Department of the Interior

U.S. Geological Survey

\title{
Geology of the Palo Alto 30 X 60 Minute Quadrangle, California: A Digital Database
}

By

E.E. Brabb' ${ }^{1}$, R.W. Graymer ${ }^{1}$, and D.L. Jones ${ }^{1}$

Open - File Report 98-348

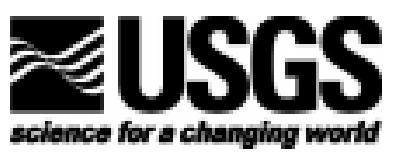

${ }^{1}$ U.S. Geological Survey, 345 Middlefield Rd., M/S 975, Menlo Park, CA 94025 


\section{U.S. Department of the Interior}

Bruce Babbitt, Secretary

\section{U.S. Geological Survey}

Thomas Casadevall, Acting Director

This report is preliminary and has not been reviewed for conformity with U.S. Geological Survey editorial standards or with the North American Stratigraphic Code. Any use of trade, product, or firm names is for descriptive purposes only and does not imply endorsement by the U.S. Government.

This database, identified as "Geology of the Palo Alto 30 X 60 minute quadrangle, California: A digital database," has been approved for release and publication by the Director of the USGS. Although this database has been subjected to rigorous review and is substantially complete, the USGS reserves the right to revise the data pursuant to further analysis and review. Furthermore, it is released on condition that neither the USGS nor the United States Government may be held liable for any damages resulting from its authorized or unauthorized use.

To obtain this pamphlet, contact: USGS Information Services

Box 25286

Denver Federal Center

Denver, CO 80225

303-202-4700

303-202-4693 FAX 


\section{Introduction}

This Open-File report is a digital geologic map database. This pamphlet serves to introduce and describe the digital data. There is no paper map included in the Open-File report. The report does include, however, PostScript plot files containing images of a geologic map sheet and an explanation sheet, as well as the accompanying text describing the geology of the area. For those interested in a paper plot of information contained in the database or in obtaining the PostScript plot files, please see the section entitled "For Those Who Don't Use Digital Geologic Map Databases" below.

This digital map database, compiled from previously published and unpublished data, and new mapping by the authors, represents the general distribution of bedrock and surficial deposits in the Palo Alto 30 X 60 minute quadrangle. Together with the accompanying text file (pageo.txt or pageo.ps), it provides current information on the geologic structure and stratigraphy of the area covered. The database delineates map units that are identified by general age and lithology following the stratigraphic nomenclature of the U.S. Geological Survey. The scale of the source maps limits the spatial resolution (scale) of the database to 1:62,500 or smaller. The content and character of the database, as well as three methods of obtaining the database, are described below.

\section{For those who don't use digital geologic map databases}

For those interested in the geology of the Palo Alto 30 X 60 minute quadrangle who do not use an ARC/INFO compatible Geographic Information System (GIS), we have provided two sets of plotfiles containing images of much of the information in the database. Each set contains an image of a geologic map sheet, an explanation sheet, and an explanatory pamphlet. There is a set of images in PostScript format and another in Adobe Acrobat PDF format (see the sections "PostScript plot files" and "PDF plot files" below).

Those interested who have computer capability can access the plot file packages in any of the three ways described below (see the section "Obtaining the digital database and plotfile packages"). However, it should be noted the plot file packages do require gzip and tar utilities to access the plot files. Therefore additional software, available free on the Internet, may be required to use the plot files (see section "Tar files").

Those without computer capability can obtain plots of the map files through USGS plot-on-demand service for digital geologic maps (see section "Obtaining plots from USGS Open-File Services") or from an outside vendor (see section "Obtaining plots from an outside vendor").

\section{Digital Open-File contents}

This Open-File report consists of three digital packages. The first is the PostScript Plotfile Package, which consists of PostScript plot files of a geologic map, explanation sheet, and geologic description. The second is the PDF Plotfile Package, and contains the same plotfiles as the first package, but in Portable Document Format (PDF). The third is the Digital Database Package, and contains the geologic map database itself, and the supporting data, including base maps, map explanation, geologic description, and references

\section{Postscript plotfile package}

This package contains the images described here in PostScript format (see below for more information on PostScript plot files):
pamap.ps
A PostScript plottable file containing an image of the geologic map and base maps of the Palo Alto 30 X 60 minute quadrangle at a scale of 1:100,000 (Sheet 1).
paexpl.ps
A PostScript plottable file containing an image of the map keys, and index maps for the Palo Alto 30 X 60 minute quadrangle (Sheet 2).
pageo.ps
A PostScript plot file of a report containing detailed unit descriptions and geological information, plus sources of data and references cited.

\section{PDF plotfile package}

This package contains the images described here in PDF format (see below for more information on PDF plot files): pamap.pdf A PDF file containing an image of the geologic map and base maps of the Palo Alto 30 X 60 minute quadrangle at a scale of 1:100,000 (Sheet 1). 

paexpl.pdf
A PDF file containing an image of
the map keys, and index maps for the Palo Alto 30 X 60 minute quadrangle
(Sheet 2).
pageo.pdf $\quad$ A PDF file of a report containing detailed unit descriptions and geological information, plus sources of data and references cited.

\section{Digital database package}

The database package includes geologic map database files for The Palo Alto 30 X 60 minute quadrangle. The digital maps, or coverages, along with their associated INFO directory have been converted to uncompressed ARC/INFO export files. ARC export files promote ease of data handling, and are usable by some Geographic Information Systems in addition to

ARC/INFO (see below for a discussion of working with export files). The ARC export files and the associated ARC/INFO coverages and directories, as well as the additional digital material included in the database, are described below:

\begin{tabular}{lll}
$\begin{array}{l}\text { ARC/INFO } \\
\text { export file }\end{array}$ & $\begin{array}{l}\text { Resultant } \\
\text { Coverage }\end{array}$ & Description of Coverage \\
\hline pa_um-py.e00 & $\begin{array}{l}\text {------- } \\
\text { pa_um-py/ }\end{array}$ & $\begin{array}{l}\text { Faults, depositional contacts, and rock units in the Palo Alto } 30 \text { X } 60 \text { minute } \\
\text { quadrangle }\end{array}$ \\
pa_um-sr.e00 & pa_um-sr/ & $\begin{array}{l}\text { Strike and dip information and fold axes in the Palo Alto } 30 \text { X } 60 \text { minute } \\
\text { quadrangle }\end{array}$
\end{tabular}

The database package also includes the following ARC coverages, and files:

ARC Coverages, which have been converted to uncompressed ARC/INFO export files:

\begin{tabular}{|c|c|c|}
\hline $\begin{array}{l}\text { ARC/INFO } \\
\text { export file }\end{array}$ & $\begin{array}{l}\text { Resultant } \\
\text { Coverage }\end{array}$ & Description of Coverage \\
\hline pa_quad.e00 & pa_quad/ & Index map of quadrangles in the Palo Alto $30 \times 60$ minute quadrangle. \\
\hline pa_um-flt.e00 & pa_um-flt/ & $\begin{array}{l}\text { Index map of faults in the Palo Alto } 30 \text { X } 60 \text { minute quadrangle with annotation } \\
\text { showing the names of major faults. }\end{array}$ \\
\hline pa_corr.e00 & pa_corr/ & Correlation table for the units in this map database. \\
\hline pa_so.e00 & pa_so/ & Sources of data index map for this map database. \\
\hline pa_as.e00 & pa_as/ & $\begin{array}{l}\text { Index map of Assemblages in the Palo Alto } 30 \mathrm{X} 60 \text { minute quadrangle. } \\
\text { (Assemblages are described in pageo.txt or pageo.ps) }\end{array}$ \\
\hline pa_um-dr.e00 & pa_um-dr/ & Drainage base map (from 1:100,000 scale original). \\
\hline pa_um-cu.e00 & pa_um-cu/ & Cultural base map (from 1:100,000 scale original). \\
\hline pa_um-topo.e00 & pa_um-topo/ & Topographic contours base map (from 1:100,000 scale original). \\
\hline
\end{tabular}

ASCII text files, including explanatory text, ARC/INFO key files, PostScript plot files, and a ARC Macro Language file for conversion of ARC export files into ARC coverages:

$\begin{array}{ll}\text { pageo.ps } & \begin{array}{l}\text { A PostScript plot file of a report containing detailed unit descriptip } \\ \text { plus sources of data and references cited. }\end{array} \\ \text { pageo.ps } & \text { A PDF version of pageo.ps. } \\ \text { pageo.txt } & \text { A text-only file containing an unformatted version of pageo.ps. } \\ \text { padb.ps } & \text { This file. } \\ \text { padb.pdf } & \text { A PDF version of padb.ps. }\end{array}$


padb.txt A text-only file containing an unformatted version of padb.ps.

import.aml ASCII text file in ARC Macro Language to convert ARC export files to ARC coverages in ARC/INFO.

The following supporting directory is not included in the database package, but is produced in the process of reconverting the export files into ARC coverages:

info/ INFO directory containing files supporting the databases.

\section{Tar files}

The two data packages described above are stored in tar (UNIX tape archive) files. A tar utility is required to extract the database from the tar file. This utility is included in most UNIX systems, and can be obtained free of charge over the Internet from Internet Literacy's Common Internet File Formats Webpage (http://www.matisse.net/files/formats.html). Both tar files have been compressed, and may be uncompressed with gzip, which is available free of charge over the Internet via links from the USGS Public Domain Software page (http://edcwww.cr.usgs.gov/doc/edchome/ndcdb/public.html). When the tar file is uncompressed and the data is extracted from the tar file, a directory is produced that contains the data in the package as described above. The specifics of the tar files are listed below:

\begin{tabular}{llll}
$\begin{array}{l}\text { Name of } \\
\text { compressed } \\
\text { tar file }\end{array}$ & $\begin{array}{l}\text { Size of } \\
\text { compressed } \\
\text { tar file } \\
\text { (uncompressed) }\end{array}$ & $\begin{array}{l}\text { Directory } \\
\text { produced when } \\
\text { extracted from } \\
\text { tar file }\end{array}$ & $\begin{array}{l}\text { Data package } \\
\text { contained }\end{array}$ \\
\hline- paps.tar.gz & $6.2 \mathrm{MB}(29.2 \mathrm{MB})$ & paps & -------- \\
papdf.tar.gz & $5.8 \mathrm{MB}(5.8 \mathrm{MB})$ & papdf & PostScript Plotfile Package \\
pa_g1.tar.gz & $6.0 \mathrm{MB}(32.0 \mathrm{MB})$ & pageo & Digital Database Package
\end{tabular}

\section{PostScript plot files}

For those interested in the geology of the Palo Alto 30 X 60 minute quadrangle who don't use an ARC/INFO compatible GIS system we have included a separate data package with three PostScript plot files. One contains a color plot of the geologic map database at 1:100,000 scale (Sheet 1, pamap.ps). The second contains a color plot of the map keys and index map (Sheet 2, paexpl.ps). Because this release is primarily a digital database, the plot files (and plots derived therefrom) have not been edited to conform to U.S. Geological Survey standards. Small units have not been labeled with leaders and in some instances map features or annotation overlap. Sample plots by the authors have proven to be quite legible and useful, however. In addition, a third PostScript file containing the geologic description and discussion is provided (pageo.ps).

The PostScript image of the geologic maps (Sheet 1) and map explanation (Sheet 2) are 44 inches wide by 34 inches high, so it requires a large plotter to produce paper copies at the intended scale. In addition, some plotters, such as those with continual paper feed from a roll, are oriented with the long axis in the vertical direction, so the PostScript image will have to be rotated 90 degrees to fit entirely onto the page. Some plotters and plotter drivers, as well as many graphics software packages, can perform this rotation. The geologic description is on 8.5 by 11 inch pages.

The PostScript plotfiles for maps were produced by the 'postscript' command with compression set to zero in ARC/INFO version 7.0.4. The PostScript plotfiles for pamphlets were produced in Microsoft Word 6.0 using the Destination PostScript File option from the Print command.

\section{PDF plot files}

We have also included a second digital package containing PDF versions of the PostScript map sheets and pamphlet described above. Adobe Acrobat PDF (Portable Document Format) files are similar to PostScript plot files in that they contain all the information needed to produce a paper copy of a map or pamphlet and they are platform independent. Their principal advantage is that they require less memory to store and are therefore quicker to download from the Internet. In addition, PDF files allow for printing of portions of a map image on a printer smaller than that required to print the entire map without the purchase of expensive additional software. All PDF files in this report have been created from PostScript plot files using 
Adobe Acrobat Distiller. In test plots we have found that paper maps created with PDF files contain almost all the detail of maps created with PostScript plot files. We would, however, recommend that those users with the capability to print the large PostScript plot files use them in preference to the PDF files.

To use PDF files, the user must get and install a copy of Adobe Acrobat Reader. This software is available free from the Adobe website (http://www.adobe.com). Please follow the instructions given at the website to download and install this software. Once installed, the Acrobat Reader software contains an on-line manual and tutorial.

There are two ways to use Acrobat Reader in conjunction with the Internet. One is to use the PDF reader plug-in with your Internet browser. This allows for interactive viewing of PDF file images within your browser. This is a very handy way to quickly look at PDF files without downloading them to your hard disk. The second way is to download the PDF file to your local hard disk, and then view the file with Acrobat Reader. We strongly recommend that large map images be handled by downloading to your hard disk, because viewing them within an Internet browser tends to be very slow.

To print a smaller portion of a PDF map image using Acrobat Reader, it is necessary to cut out the portion desired using Acrobat Reader and the standard cut and paste tools for your platform, and then to paste the portion of the image into a file generated by another software program that can handle images. Most word processors (such as Microsoft Word) will suffice. The new file can then be printed. Image conversion in the cut and paste process, as well as changes in the scale of the map image, may result in loss of image quality. However, test plots have proven adequate.

\section{Digital database format}

The databases in this report were compiled in ARC/INFO, a commercial Geographic Information System (Environmental Systems Research Institute, Redlands, California), with version 3.0 of the menu interface ALACARTE (Fitzgibbon and Wentworth, 1991, Fitzgibbon, 1991, Wentworth and Fitzgibbon, 1991). The files are in either GRID (ARC/INFO raster data) format or COVERAGE (ARC/INFO vector data) format. Coverages are stored in uncompressed ARC export format (ARC/INFO version 7.x). ARC/INFO export files (files with the .e00 extension) can be converted into ARC/INFO coverages in ARC/INFO (see below) and can be read by some other Geographic Information Systems, such as MapInfo via ArcLink and ESRI's ArcView (version 1.0 for Windows 3.1 to 3.11 is available for free from ESRI's web site: http://www.esri.com). The digital compilation was done in version 7.0.4 of ARC/INFO with version 3.0 of the menu interface ALACARTE (Fitzgibbon and Wentworth, 1991, Fitzgibbon, 1991, Wentworth and Fitzgibbon, 1991).

\section{Obtaining the Digital Database and Plotfile Packages}

The digital data can be obtained in any of three ways:

a. From the Western Region Geologic Information Web Page.

b. Anonymous ftp over the Internet

c. Sending a tape with request

\section{To obtain tar files of database or plotfile packages from the USGS web pages:}

The U.S. Geological Survey now supports a set of graphical pages on the World Wide Web. Digital publications (including this one) can be accessed via these pages. The location of the main Web page for the entire USGS is

http://www.usgs.gov

The Web server for digital publications from the Western Region is

http://wrgis.wr.usgs.gov

Go to

http://wrgis.wr.usgs.gov/open-file/of98-348

to access this publication. Besides providing easy access to the entire digital database, the Western Region Web page also affords easy access to the PostScript plot files for those who do not use digital databases (see below).

To obtain tar files of database or plotfile packages by ftp: 
The files in these reports are stored on the U.S. Geological Survey Western Region FTP server. The Internet ftp address of this server is:

$$
\text { ftp://wrgis.wr.usgs.gov }
$$

The user should log in with the user name 'anonymous' and then input their e-mail address as the password. This will give the user access to all the publications available via ftp from this server.

The files in this report are stored in the subdirectory:

pub/open-file/of98-348

\section{To obtain tar files of database or plotfile packages on tape:}

Database files, PostScript plotfiles, and related files can be obtained by sending a tape with request and return address to:

Palo Alto 30 X 60 minute quadrangle Geologic Database

c/o Database Coordinator

U.S. Geological Survey

345 Middlefield Road, M/S 975

Menlo Park, CA 94025

Do not omit any part of this address!

NOTE: Be sure to include with your request the exact names, as listed above, of the tar files you require. An Open-File Report number is not sufficient, unless you are requesting both the database package and plotfile package for the report.

The compressed tar file will be returned on the tape. The acceptable tape types are:

2.3 or $5.0 \mathrm{~GB}, 8 \mathrm{~mm}$ Exabyte tape.

\section{Obtaining plots from a commercial vendor}

Those interested in the geologic map of the Palo Alto 30 X 60 minute quadrangle, but who use neither a computer nor the Internet, can still obtain the information. We will provide the PostScript plot files on digital tape (details below) for use by commercial vendors who can make large-format plots. Send a blank tape with request and return address to:

Palo Alto 30 X 60 minute quadrangle Geologic Map Plotfiles

c/o Database Coordinator

U.S. Geological Survey

345 Middlefield Road, M/S 975

Menlo Park, CA 94025

Do not omit any part of this address!

The compressed tar file will be returned on the tape. The acceptable tape types are:

2.3 or $5.0 \mathrm{~GB}, 8 \mathrm{~mm}$ Exabyte tape.

Make sure your vendor is capable of reading these tape types and PostScript plot files. Important information regarding tape file format is included in the sections "Database Release Format," "Tar Files," and "PostScript Plot Files" above, so be certain to provide a copy of this document to your vendor.

\section{Obtaining plots from USGS Open-File Services}


NOTE: As of this writing, plot-on-demand is not available from USGS. It is anticipated later in

1998.

U.S. Geological Survey is planning to provide a plot-on-demand service for map files, such as those described in this report, through Open-File Services. In order to obtain plots, contact Open-File Services at:

\author{
USGS Information Services \\ Box 25286 \\ Denver Federal Center \\ Denver, CO 80225-0046
}

(303) 202-4200

1-800-USA-MAPS

FAX: (303) 202-4695

e-mail: infoservices@usgs.gov

Be sure to include with your request the Open-File Report number and the exact names, as listed in the Database Contents section above, of the plotfiles you require. An Open-File Report number and its letter alone may not be sufficient, unless you are requesting plots of all the plotfiles for that report.

\title{
Converting ARC export files
}

ARC export files are converted to ARC coverages using the ARC command IMPORT with the option COVER. To ease conversion and maintain naming conventions, we have included an ASCII text file in ARC Macro Language that will convert all of the export files in the database into coverages and create the associated INFO directory. From the ARC command line type:

Arc: \&run import.aml

ARC export files can also be read by some other Geographic Information Systems. Please consult your GIS documentation to see if you can use ARC export files and the procedure to import them.

\section{Digital compilation}

The geologic map information was digitized from stable originals of the geologic maps at 1:24,000 and 1:62,500 scale. The author manuscripts (pencil on mylar) were scanned using a Altek monochrome scanner with a resolution of 800 dots per inch. The scanned images were vectorized and transformed from scanner coordinates to projection coordinates with digital tics placed by hand at quadrangle corners. The scanned lines were edited interactively by hand using ALACARTE, color boundaries were tagged as appropriate, and scanning artifacts visible at 1:24,000 were removed.

\section{Base maps}

Base Map layers were prepared from scale-stable printing negatives of the U.S. Geological Survey Palo Alto (1982 edition) 1:100,000 topographic map, which has a 50 meter contour interval. Scanned and vectorized images were transformed from scanner coordinates to projection coordinates with digital tics placed by hand at map corners. The images were then trimmed interactively by hand using ALACARTE to conform to the area of the geologic coverages. Small mismatches at the boundaries caused by slight differences in the original scans remain in the three base map coverages. These base map layers are digital images but no information other than location is attached to the lines. The base maps are provided for reference only.

\section{Faults and landslides}

This map is intended to be of general use to engineers and land-use planners. However, its small scale does not provide sufficient detail for site development purposes. In addition, this map does not take the place of fault-rupture hazard zones designated by the California State Geologist (Hart and Bryant, 1997). Similarly, the database cannot be used to identify or delineate landslides in the region. For a depiction of landslide distribution, see Brabb and Pampeyan (1972), Brabb and others (1978), Cooper-Clark and Associates (1975), Mark (1992), Wieczorek and others (1985), and Wieczorek and others (1988). 


\section{Spatial resolution}

Uses of this digital geologic map should not violate the spatial resolution of the data. Although the digital form of the data removes the constraint imposed by the scale of a paper map, the detail and accuracy inherent in map scale are also present in the digital data. The fact that this database was edited at a scale of 1:24,000 means that higher resolution information is not present in the dataset. Plotting at scales larger than 1:24,000 will not yield greater real detail, although it may reveal finescale irregularities below the intended resolution of the database. Similarly, where this database is used in combination with other data of higher resolution, the resolution of the combined output will be limited by the lower resolution of these data. Note that in contrast to the geologic coverages, the base map layers have a resolution of 1:100,000, so significant discrepancies with the geologic coverages are possible. The base map layers are provided for reference only.

\section{Database specifics}

The map databases consist of ARC coverages and supporting INFO files, which are stored in a UTM (Universal Transverse Mercator) projection (Table 1). Digital tics define a 2.5 minute grid of latitude and longitude in the geologic coverages corresponding with quadrangle corners and internal tics. In the base map layers, the tics define a 7.5 minute grid, corresponding with quadrangle corners.

Table 1 - Map Projection

The maps are stored in UTM projection

PROJECTION UTM
UNITS METERS
ZONE 10
PARAMETERS
END

-on the ground

-UTM zone

The content of the geologic database can be described in terms of the lines and the areas that compose the map. Descriptions of the database fields use the terms explained in Table 2.

Table 2 - Field Definition Terms

\begin{tabular}{|c|c|}
\hline ITEM NAME & name of the database field (item) \\
\hline WIDTH & maximum number of digits or characters stored \\
\hline OUTPUT & output width \\
\hline TYPE & $\begin{array}{l}\text { B-binary integer, F-binary floating point number, } \\
\text { I-ASCII integer, C-ASCII character string }\end{array}$ \\
\hline $\begin{array}{l}\text { N. DEC. } \\
\text { point numbers }\end{array}$ & number of decimal places maintained for floating \\
\hline
\end{tabular}

\section{Lines}

The lines (arcs) are recorded as strings of vectors and are described in the arc attribute table (Table 3). They define the boundaries of the map units, the boundaries of open bodies of water, and the map boundaries. These distinctions, including the geologic identities of the unit boundaries, are recorded in the LTYPE field according to the line types listed in Table 4.

Table 3 - Content of the Arc Attribute Tables

\begin{tabular}{|c|c|c|c|c|c|}
\hline ITEM NAME & WIDTH & OUTPUT & TYPE & N. DEC & \\
\hline FNODE\# & 4 & 5 & B & & starting node of arc (from node) \\
\hline TNODE\# & 4 & 5 & B & & ending node of arc (to node) \\
\hline LPOLY\# & 4 & 5 & B & & polygon to the left of the arc \\
\hline RPOLY\# & 4 & 5 & B & & polygon to the right of the arc \\
\hline LENGTH & 4 & 12 & $\mathrm{~F}$ & 3 & length of arc in meters \\
\hline$<$ coverage $>\#$ & 4 & 5 & B & & unique internal control number \\
\hline <coverage>-ID & 4 & 5 & B & & unique identification number \\
\hline LTYPE & 35 & 35 & $\mathrm{C}$ & & line type (see Table 4$)$ \\
\hline SEL & 1 & 1 & I & & user defined field used to save a selected set \\
\hline SYMB & 3 & 3 & I & & $\begin{array}{l}\text { user defined field used to save symbol } \\
\text { assignments (such as color) }\end{array}$ \\
\hline
\end{tabular}


Table 4 - Line Types Recorded in the LTYPE Field

$$
\begin{gathered}
\text { contact, certain } \\
\text { contact, concealed } \\
\text { contact, approx. located } \\
\text { fault, certain } \\
\text { fault, concealed } \\
\text { fault, concealed, queried } \\
\text { fault, approx. located } \\
\text { fault, inferred } \\
\text { reverse fault, certain } \\
\text { reverse fault, concealed } \\
\text { scratch boundary } \\
\text { water boundary } \\
\text { map boundary }
\end{gathered}
$$

\begin{tabular}{|c|c|c|c|c|c|}
\hline AREA & 4 & 12 & $\mathrm{~F}$ & 3 & area of polygon in square meters \\
\hline PERIMETER & 4 & 12 & $\mathrm{~F}$ & 3 & length of perimeter in meters \\
\hline$<$ coverage $>\#$ & 4 & 5 & B & & unique internal control number \\
\hline <coverage>-ID & 4 & 5 & B & & unique identification number \\
\hline PTYPE & 35 & 35 & $\mathrm{C}$ & & unit label \\
\hline SEL & 1 & 1 & I & & user defined field used to save a selected set \\
\hline SYMB & 3 & 3 & I & & $\begin{array}{l}\text { user defined field used to save symbol } \\
\text { assignments (such as color) }\end{array}$ \\
\hline
\end{tabular}

The geologic linetypes are ALACARTE line types that correlate with the geologic line symbols in the ALACARTE line set GEOL61.LIN according to the ALACARTE lines lookup table (GEOL61.LUT).

\section{Areas}

Map units (polygons) are described in the polygon attribute table (Table 5) The identities of the map units from compilation sources are recorded in the PTYPE field by map label (Table 6). Map units are described more fully in the accompanying text file pageo.txt or pageo.ps. Note that ARC/INFO coverages cannot contain both point and polygon information, so only coverages with polygon information will have a polygon attribute table, and these coverages will not have a point attribute table.

Table 5 - Content of the Polygon Attribute Tables

ITEM NAME WIDTH OUTPUT TYPE N. DEC

Table 6 - Map Units

(See pageo.txt or pageo.ps for descriptions of units)
$\mathrm{H} 2 \mathrm{O}$
$\mathrm{Jgb}$
Jsv
KJf
KJs
$\mathrm{KJV}$
$\mathrm{Ka}$
Kgr
Kpp
Ks
Ksh
QTm
QTsc
Qal
$\mathrm{Qb}$
Qc

Qcl
Qhaf
Qhasc
Qhb
Qhbd
Qhbm
Qhfp
Qhl
Qhsc
Qm
Qmt
Qof
Qpaf
Qpaf1
Qpoaf
Qs

Tla

Tlo

Tls

Tm

Tmb

$\mathrm{Tp}$

Tpl

Tpm

Tpp 


$\begin{array}{lll}\text { Tpt } & \text { Tuv } & \mathrm{fm} \\ \text { Tptu } & \text { Tvq } & \mathrm{fs} \\ \text { Tsc } & \text { Tw } & \mathrm{fsr} \\ \text { Tsl } & \text { af } & \mathrm{m} \\ \text { Tsm } & \text { alf } & \mathrm{sp} \\ \text { Tsr } & \text { fc } & \\ \text { Tss } & \text { fcg } & \\ \text { Tst } & \text { fg } & \\ \text { Tus } & \text { fl }\end{array}$

\section{Acknowledgments}

We are grateful to the following U.S. Geological Survey paleontologists who have examined our fossils and provided ages necessary to establish the stratigraphic sequence and structure: David Bukry (Cretaceous and Tertiary nannoplankton), Kristin McDougall (Tertiary foraminifers), William Sliter (deceased - Cretaceous and Eocene foraminifers), John Barron (Tertiary diatoms), Charles Powell II (Tertiary mollusks), and Bonita Murchey (Mesozoic radiolaria).

We are also very grateful to managers and staff of Chevron, EXXON, UNOCAL, ARCO, and Shell Petroleum Companies who have provided reports, maps, picked slides, and residues for about 25,000 microfossil localities in the San Francisco Bay Region.

We are grateful to Tracey Felger, who made the original scan and a preliminary edit of author materials; to Judy Mariant, who did additional editing and tagging of lines; and to Dominique Garnier, who digitized many of the bedding attitudes. Carl Wentworth kindly provided advice on digitizing and editing procedures. Ed Helley provided materials and advice on Quaternary units.

\section{References Cited}

Brabb, E.E., and Pampeyan, E.H., 1972, Preliminary map of landslide deposits in San Mateo County, California: U.S. Geological Survey Miscellaneous Field Studies Map MF-344, scale 1:62,500.

Brabb, E.E., Pampeyan, E.H., and Bonilla, M.G., 1978, Landslide susceptibility in San Mateo County, California: U.S. Geological Survey Miscellaneous Field Studies Map MF-360, scale 1:62,500.

Cooper-Clark and Associates, 1975, Preliminary map of landslide deposits in Santa Cruz County, California in Seismic Safety Element: Santa Cruz, California, Santa Cruz County Planning Department, 132 p.

Fitzgibbon, T.T., 1991, ALACARTE installation and system manual (version 1.0): U.S. Geological Survey Open-File Report 91-587B.

Fitzgibbon, T.T., and Wentworth, C.M., 1991, ALACARTE user interface - AML code and demonstration maps (version 1.0): U.S. Geological Survey Open-File Report 91-587A.

Hart, E.W., and Bryant, W.A., 1997, Fault-rupture hazard zones in California; Alquist-Priolo Special Studies Zones Act of 1972 with index to special studies zones maps: California Division of Mines and Geology Special Publication 42, revised 1997.

Mark, R.K., 1992, Map of debris-flow probability, San Mateo County, California: U.S. Geological Survey Miscellaneous Investigations Map I-1257-M, 2 sheets, scale 1:62,500.

Wentworth, C.M., and Fitzgibbon, T.T., 1991, ALACARTE user manual (version 1.0): U.S. Geological Survey Open-File Report 91-587C.

Wieczorek, G.F., Harp, E.L., Mark, R.K., and Bhattacharyya, A.K., 1988, Debris flows and other landslides in San Mateo, Santa Cruz, Contra Costa, Alameda, Napa, Solano, Sonoma, Lake, and Yolo Counties, and factors influencing debris-flow distribution in Ellen, S.D., and Wieczorek, G.F., eds., Landslides, floods, and marine effects of the storm of January 3-5, 1982, in the San Francisco Bay region, California: U.S. Geological Survey Professional Paper 1434, p. 133-162.

Wieczorek, G.F., Wilson, R.C., and Harp, E.L., 1985, Map showing slope stability during earthquakes in San Mateo County, California: U.S. Geological Survey Miscellaneous Investigations Map I-1257-E, scale 1:62,500. 